\title{
Designing a better learning environment with the Web - problems and prospects
}

\author{
Andrew Dillon \\ HCI Lab \\ SLIS \\ Indiana University \\ Bloomington IN 47405 \\ adillon@indiana.edu \\ http://memex.lib.indiana.edu/adillon/adillon.html \\ published in CyberPsychology and Education, 3, 1, 2000
}

This item is not the definitive copy. Please use the following citation when referencing this material: Dillon, A. (2000) Designing a better learning environment with the Web: problems and prospects. CyberPsychology and Behavior, 3(1), 97-102.

\section{Introduction}

In a recent review of the empirical findings on hypermedia and learning outcomes, Dillon and Gabbard (1998) concluded that contrary to many people's assumptions, the use of hypermedia-based instructional systems in education had not produced significant learning gains. Indeed, their review concluded that such instructional technologies rarely showed any benefit for learners over existing paper- or lecture-based instructions. While it is commonplace these days to dismiss as irrelevant any media comparison study, the Dillon and Gabbard review went further, also examining comparisons made between alternative hypermedia implementations (a within-media comparison) and between single and group learners employing this technology. Since hypermedia is the underlying technology of the World Wide Web, their findings made depressing reading for those of us who believe that this technology is important and could be put to powerful instructional use.

The present issue contains papers from many leading theorists who advocate the use and exploitation of information technologies such as hypermedia and the World-Wide Web in our classrooms, and I am not completely in disagreement with them. However, I wish to 
question the very assumptions on which the use of the Web and standalone hypermedia applications are based. What I aim to provide in this paper is a sense of the gaps in our knowledge, and to speculate on why education is so poorly served by the wonderful technologies that are within our grasp.

Two major claims are made:

1) the application of educational technology is poorly served by the field's weak analysis and limited understanding of the basic human engineering issues of usability and usercentered design;

2) the theoretical analysis of learning is unnecessarily partitioned into competing grand views, or paradigms, that place less emphasis on empirical analysis of learning and more on reifying the field of education.

This is no Luddite treatise. It is a call to arms; a request for proponents to challenge assumptions about learning technologies, to test the claims made for them, to design instructional technologies in a learner-centered manner.

\section{Why the World Wide Web?}

On one hand it is easy to get caught up in the hype of the Web. After all, it is a marvel of information access, worldwide connectivity, and even, in some rare cases, ease-of-use. There has never been an information technology quite like it and it is tempting to dismiss the nay-sayers as ignorant stick-in-the-muds, clinging to outdated views of computers, teaching and learning. But a closer look at the Web and variant hypermedia-based technologies that aim to support education through cyberspace throws up some interesting questions that require more serious consideration.

One such question is why the Web should offer us anything special for instruction? After all, since when did information access and presentation equate to instruction? We can incorporate more information for learners to explore, navigable by link structures, and this certainly can enable greater and faster access to more information than most 
educational libraries provide, but is this enough to ensure learning? We can communicate over a distance, allowing isolated individuals to form groups, to contact experts, and to share information in real-time and off-line. Again, this could all be done by older technologies but that is not my major concern, since the Web is surely a more attractive, powerful and responsive environment for these activities. My concern is the relevance of such capabilities to learning.

In my view, while these features are certainly major drivers towards acceptance of Web technology by a large user population, none of the above advantages are in themselves major drivers of learning outcome. This is crucial since, if true, it seems that the lure of the Web has little or anything to do with learning. If we try to understand why educationalists are so enamoured of links and nodes then we need to look elsewhere. Consider, for example, the type of claim made for Web technology in the learning context. It is seen as a breakthrough in cognitive compatibility, more natural, more learner-centric, more adaptable, more flexible etc. than any previous technology (see Dillon, 1996 for a review of the claims). Each of these claims ought to be examined critically by educationalists but too often they are assumed, taken for granted as obvious or self-evident truths. Evidence in their favor is normally anecdotal, rarely, if ever, derived from well-controlled studies. After more than 50 years of existence as a field of enquiry, this is a poor state of affairs for educational technology.

Unintended consequences of technologies always follow any implementation (e.g., the ease of communication afforded by email has the effect of swamping some experts with innumerable requests, frequently trivial ones that could be answered with existing resources). Technologies are frequently designed with little consideration of usability, yet it is good human factors design that at least ensures the primary advantages of technology (mentioned above) can be exploited. Perhaps even more worrying, there is little consideration of the measurable learning advantages that might accrue from Web use, greater emphasis being placed on preference than performance, despite evidence that these two variables may contradict each other in interactive tasks (Bailey, 1993). 
Does the Web have a place in education? Of course it does but to gain that place requires effort is spent on design, testing and refinement of resources which are targeted appropriately at learning contexts likely to benefit. You cannot develop a reasoned case or argument by merely stringing words together, yet it appears that just offering information via web links is all that is needed to make an online learning environment. Just as the thesis needs to refine, build and sequence ideas, using words and figures as bricks in a planned, meaningful fashion to construct a case, so does a Web environment require planning, organization and revision in order to convey structure and offer instruction. Web-based instruction has a long way to go before it can compete. Any headlong rush to embrace the technology as a panacea for instructional design is flawed and fanatical.

\section{Building for use - the human factors of interaction}

The Web is here and it will not go away. So how can we best exploit it? In the first instance, any interactive technology must be designed for usability by which I mean we must consider the effectiveness, efficiency and satisfaction with which the intended users can employ the technology. To do this we must design for learning contexts, meaning we must analyze our learners, their instructors, the tasks to be supported and the physical and social environment in which the learning is to occur. Twenty years of research into human-computer interaction (HCI) has shown that without such analyses, the chances of ever developing a technology that is accepted by users and yields the desired benefits are significantly reduced.

While I suspect few instructional technologists would disagree with the paragraph above, I contend that too few of them will have studied the human factors findings on interaction

sufficiently deeply to learn the lessons it might impart. It surprises many to find that there is an extensive empirical literature on usability and usefulness which explains, for example, why people read up to $30 \%$ slower on screen, why users experience significantly greater disorientation with hypermedia than with paper, that users tend to imbue human characteristics to software, or what determines long-term user acceptance of new technologies. This literature is not largely the work of instructional technologists, 
but its relevance to their goals is undeniable. Too often it seems, learning technologies are designed without any proper addressing of the factors that are important to usable and useful design and implementation. Some times these technologies are even designed in contradiction to these factors. This paper is not the appropriate vehicle for a review of that literature, but the interested reader would do well to consult such resources as Helander et al (1997) or Dillon (1994) for basic reviews.

An interaction analysis makes us focus first and foremost on the activities a learner will perform and I believe this is a key reason for the failure of HCI findings to break into the instructional domain where current conceptions of learning are attempting to move away from traditional instructional models predicated on narrow tasks or prescribed task sequences. Indeed, there is at least a superficial similarity between the HCI approach to design analysis and the behavioral objectives tradition of 1960s instructional design. However, I would suggest there is at least one major difference. HCI does not equate performance in using the technology with learning. Rather it is a necessary but insufficient component of the learning scenario. Learning is a complex, multiplydetermined activity or process which cannot just be equated with a single task such as information retrieval, target location, navigation or memorization alone. Yet part of learning involves the active engagement of those tasks - and if the technology interferes, slows down or otherwise raises usability obstacles in the path of learners, then this will negatively affect education.

In this sense, learning, as a goal, needs to be addressed at a level where aspects of information location, summarization of ideas, linking, memory etc., may be identified are components. Such a componential analysis is essential to the appropriate technological support of the learner. In so designing the technological support (hypertextual, Webbased or otherwise), empirical methods can be employed to determine usability, to rectify design problems and to assess the extent to which the technology increases learner performance on that component (although this is usually a different issue from whether or not learning was being supported). The complete instructional analysis then takes account of the necessary performance components or tasks to be included and sequenced in the 
learning environment so as to ensure learning goals are attained. In short, interaction analysis becomes a part of instructional analysis.

This is by no means a complete recipe for success, but it is a tight form of design rationale that yields demonstrable benefits and ensures that re-design can be maximally targeted to produce the greatest effects. Many instructional technologies would be improved by adopting this style of design at some point in their development to avoid the situation where a fine instructional system is significantly hampered by poor implementation of the user interface. What is required to put this approach to use is not only an understanding of the interaction literature and findings, but also a strong theoretical analysis of learning that would guide the earliest conceptions of design and encourage new ideas for the technological support of education - which leads me to my second claim.

\section{The competition of education theories}

Clearly the problem of designing successful web-based learning environments rests on more than simply applying HCI principles. Theoretical insights into learning are crucial to improving our designs and understanding how we can advance education. Indeed, as I have argued elsewhere, there can never be a purely empirical approach to design - any artifact must be its nature embody the theoretical assumptions of its designers, whether these be consciously and clearly articulated or not (Dillon, 1995). What is required of any theory to be helpful in this domain is its applicability to design in a manner that can drive development.

Space precludes a detailed exploration of the application of educational theory to design, but it is necessary to point out that the major concerns of educational theorists, as evinced in the theoretical literature of the field, are less with the problems of explaining the findings of learning outcome with various media and more with offering broad conceptual frameworks of learning. Much educational theorizing is given over to proposing one or other broad model of learning or countering the critiques of other broad model proponents. To an outsider, the rather heated debates between constructivists and 
behaviorists are bewildering, seeming more concerned with attracting adherents to a cause rather than to enlightening our analyses of education. Furthermore, both points of view seem to attack stereotyped notions of learning and cognition that are outdated and long past interest to most cognitive and social scientists.

As mentioned above, the emphasis on understanding the context within which learning occurs is crucial to good technology design. Such an emphasis precludes any reliance on an overarching theoretical position that seeks to represent the workings of the human mind as a mass of stimulus-response arcs, a semantic network or an attuned rhizome. Invoking a learning scenario serves to ground the interaction literature. It also ensures that generalization of findings is bounded to the context of use examined.

What is really lacking in our work is a means of plugging the gaps in our knowledge, a framework for inference and potential generalization of findings beyond the exact context of measurement. This is the type of role theory plays in a mature science. Even if we refuse to acknowledge education as a science, there can surely be no argument that useful theory would advance our understanding of the technologies we create for instruction. Yet many current theoretical positions in education seem far removed from these practical concerns, leaving technology designers to guess or intuit the appropriate means of implementing a learning tool. Worse than that, certain theoretical positions are so loosely articulated that they enable designers to invoke theoretical support independent of its demonstrable application.

It is not just the debate over constructivism, cognitivism or behaviorism that limits us. The latest edition of the award-winning Handbook of Research for Educational Communications and Technology (Jonassen (ed.), 1996) provides separate treatments of behaviorism, systems theory, communication theory, cognition, sociology, constructivism, ecological psychology, critical theory and post-modernism. Each makes a case for the value of its theoretical position for education, outlining its origins, basic assumptions and constructs, while only limited attempts are made to link these to specific technological issues. Even where technology is invoked, the examples are frequently narrative in nature, not empirical or prescriptive. Little effort is made to bridge these 
theoretical divides either, to show how the importance of context is shared by many theories or to make explicit the idea that a learner must be both a cognitive and social being (how could a human ever be otherwise?). In a nutshell, the theories of the field place emphasis on too many high level claims about the ultimate nature of learning and the human mind, and provide too little analysis of how theory might guide instructional technology design. We need to ground ourselves as a field and to emphasize data over opinion, and to use theory as a strong adjunct to our investigations and technology designs (see e.g., an excellent attempt at this in the work of Carroll, 1998). Only then will the field advance.

\section{The way forward?}

Will we one day have universities without walls, virtual classrooms, and distributed networks of scholars and students? Almost certainly. To paraphrase Ted Nelson's arguments for hypermedia - the question is not if or when, but how can we make them great. I've pointed out that while we seem to be on an inevitable course towards greater use of technology, we are limping along, not progressing in leaps and bounds. While I believe we can take greater strides if we address some basic interaction issues immediately, there remain worrying theoretical shortcomings to our designs that warrant our serious consideration.

If we are content as a field to follow technologists and their inventions, hoping to eventually refine our new environments into shape then progress will be slow, and generations of learners may have to suffer our mistakes en route. Even then, I fear we will always look towards new technologies to solve old problems. There has to be a better way - and they way demands theoretical analysis at the contextual and performance levels. Without this, the virtual university will be the actual business that many of us currently in education fear physical universities are in danger of becoming: the home of industry-dictated courses and purchasable degrees. There is a better way. 


\section{References}

Bailey, G. (1993) Performance vs. Preference. Proc. of the Human Factors Society Annual Conference New York: HFES, 316-320.

Carroll, J. (ed.) (1998) Minimalism beyond the Nurnberg Funnel. Cambridge: MIT Press.

Dillon, A. (1995) Artifacts as theories: Convergence through user-centered design. Proceedings of the American Society for Information Science Annual Conference. Also available at http://www.slis.indiana.edu/adillon/adillon-artifacts.html

Dillon, A. (1996) Myths, misconceptions and an alternative perspective on information usage and the electronic medium. In: Rouet, J-F (et al) eds. Hypertext and Cognition. LEA: Mahaw NJ.

Dillon, and Gabbard (1998) Hypermedia as an educational technology: a review of the quantitative research literature on learner comprehension, control and style

Review of Educational Research, 68,3, 322-349 (Fall 1998)

Helander, M., Landauer, T., Prabhu, P. (Eds.) (1997) Handbook of Human-Computer Interaction, 2nd edition, Amsterdam: Elsevier Science Ltd.

Jonassen, D. (ed.) Handbook of Research on Educational Communications and Technology. New York: Macmillan. 